\title{
Study of Dyslipidemia in Iraqi Hypertension Patients in Tikrit City
}

\author{
Zaidan Jayed Zaidan', Ahmed Moyed Hussein ${ }^{2}$, Sheet Mutlak Ahmed ${ }^{3}$ \\ ${ }^{l}$ Prof. ass. Internal medicine-Department of Medicine-College of Medicine-Tikrit University-Tikrit-Iraq, \\ ${ }^{2}$ Interventional cardiologist, lecturer-Department of Medicine-Ninevah College of Medicine-Mosul-Iraq, \\ ${ }^{3}$ Interventional cardiologist-Cardiology center-Tikrit Teaching Hospital-Tikrit-Iraq.
}

\begin{abstract}
Background: Hypertension is prevalent all over the world and represent a major health problem. Dyslipidemia is a major cause of cardiovascular morbidity and mortality. There is a correlation between hyperlipidemia and hypertension.
\end{abstract}

Aim of study: to find out the prevalence of dyslipidemia in Iraqi hypertension patients, and to find out how many of them on statin therapy, and how many reach target according to the last guidelines

Patients and methods: a cross-sectional study conducted in outpatient clinic in Salahaddin General Hospital in Tikrit City. About 344 hypertensive patients were included in this study. A questionnaires including general information about patients were filled and venous blood was drawn from every patient and sent for hospital lab to measure necessary investigations. ASCVD risk score was calculated for every patient by ASCVD Risk Estimator Plus. Then data were analyzed by application of Microsoft excel program and Statistical Package for Social Sciences (SPSS) version 23.

Results: (49\%) of hypertension patients had total cholesterol of $>200 \mathrm{mg} / \mathrm{dl},(63.4 \%)$ had LDL of $\geq 115 \mathrm{mg} /$ $\mathrm{dl}$, (57.6\%) had HDL of $<40 \mathrm{mg} / \mathrm{dl}$, and (54.1\%) had triglycerides of $\geq 150 \mathrm{mg} / \mathrm{dl}$. Smoker patients in this study had highest ASCVD risk score (12.65 $\pm 6.63 \%)$ followed by former smokers $(7.36 \pm 3.56 \%)$ and nonsmokers $(6.02 \pm 4.16 \%)$. Only $76(22.1 \%)$ of hypertension patients were on statin therapy for hyperlipidemia and only 18 (23.7\%) of them reaching target LDL level according to 2016 ESC/EAS guidelines. While 268 (77.9\%) of hypertension patients had no statin therapy and only 65 (24.3\%) of them had LDL level within target.

Conclusion: Hyperlipidemia is very prevalent in hypertension patients in Tikrit City, despite that only one of five receiving treatment and only one of four from those who received treatment reaching the target of LDL level according to 2016 ESC/EAS guidelines, and three of four of those who are on no treatment are out of the target. This is a major health problem need attention.

Keywords: Hypertension, Dyslipidemia, Cholesterol, HDL, LDL, Triglycerides

\section{Introduction}

Hypertension can be defined as an abnormally high arterial blood pressure. It is still accepted that

\section{Corresponding author:}

Zaidan Jayed Zaidan,

Prof. ass. Internal Medicine- Department of Medicine-

College of Medicine-Tikrit University-Tikrit-Iraq.

Email: zaidanjaydz@gmail.com,

Phone: 009647719330585 hypertension defined as systolic blood pressure $\geq 140$ $\mathrm{mm} \mathrm{Hg}$ and/or diastolic blood pressure $\geq 90 \mathrm{~mm} \mathrm{Hg}{ }^{[1-}$ 3]. Because of its prevalence, hypertension represent a major health problem ${ }^{[4-7]}$. Hypertension affect about $32.6 \%$ of US population above 20 years of age ${ }^{[8]}$. In Iraq , about $35.6 \%$ of population above 18 years of age have hypertension ${ }^{[9]}$. Worldwide, dyslipidemia is a major cause of cardiovascular morbidity and mortality [10, 11]. Atherosclerosis is a progressive pathological process that lead to heart and cerebrovascular diseases ${ }^{[12,13]}$ an dyslipidemia is a major risk factor of atherosclerosis. 
About $39.6 \%$ of Iraqi population above 18 years of age have raised cholesterol or currently on statin treatment ${ }^{[9]}$. There is a correlation between hyperlipidemia , hypertension and pulse pressure ${ }^{[14]}$.

The aim of this study: to find out the prevalence of dyslipidemia in Iraqi hypertension patients, and to find out how many of them on statin therapy, and how many reach target according to the last guidelines.

\section{Patients and method}

This is a cross-sectional study conducted in outpatient clinic in Salahaddin General Hospital in Tikrit City, from $1^{\text {st }}$ of January 2019 to $31^{\text {st }}$ of May 2019. All established hypertension patients above 25 years of age that agreed to participate in this study were included.

Exclusion criteria: Patients with: established coronary or valvular heart disease, chronic kidney disease, diabetes mellitus, stroke or peripheral vascular disease were excluded.

About 344 hypertensive patients were included in this study after an oral informed consent taken from every patient . $156(45.3 \%)$ of them were males, and 188 $(54.7 \%)$ were females. Age range from (30-80) years with mean age of $(50.34 \pm 10.35)$ years. Every patient was reviewed individually by a questionnaire including general information about patients beside smoking state and history of : cardiovascular disease, diabetes mellitus, chronic kidney disease or peripheral vascular disease, and history of treatment of dyslipidemia. Weight (Wt) and height $(\mathrm{Ht})$ of every patient was recorded and body mass index (BMI) was calculated. Systolic and diastolic blood pressure of each patient was also recorded. Then $5 \mathrm{ml}$ of venous blood was drawn from every fasting (for 14 hours) patient in this study and sent directly to hospital lab for measuring : fasting blood sugar, blood urea and serum creatinine to exclude diabetic patients and patients with Chronic kidney disease. Lipid profile including: serum total cholesterol, low density lipoprotein (LDL), high density lipoprotein (HDL), very low density lipoprotein (vLDL) and serum triglycerides were also measured.

Then atherosclerosis cardiovascular disease (ASCVD) risk was calculated for every patient by ASCVD Risk Estimator Plus, an application provided by American College of Cardiology (ACC). Then patients were grouped into 4 groups: 1- low risk with ASCVD risk score of $<1 \%$, 2- moderate risk with ASCVD risk score of $\geq 1 \%$ and $<5 \%, 3$ - high risk with ASCVD risk score of $\geq 5 \%$ and $<10 \%$ and 4 - very high risk with ASCVD risk score of $\geq 10 \%$ according to European Society of Cardiology (ESC) and European Atherosclerosis Society (EAS) 2016 guidelines for the management of dyslipidaemias ${ }^{[15]}$.

Then data were analyzed by application of Microsoft excel program and Statistical Package for Social Sciences (SPSS) version 23. Outcomes of analysis were arranged into tables and figure. P-value was calculated by different probability tests.

\section{Results}

About 344 hypertensive patients were included in this study. $156(45.3 \%)$ of them were males, and 188 $(54.7 \%)$ were females. Age range from $(30-80)$ years with mean age of $(50.34 \pm 10.35)$ years. FB. sugar mean $\pm \mathrm{SD}$ was $(93.00 \pm 0.00 \mathrm{mg} / \mathrm{dl})$, B. urea mean $\pm \mathrm{SD}$ was $(33.79 \pm 6.82 \mathrm{mg} / \mathrm{dl})$, and $\mathrm{S}$. creatinine mean $\pm \mathrm{SD}$ was $(0.83 \pm 0.15 \mathrm{mg} / \mathrm{dl})$.

About 171 patients (49\%) had total cholesterol of $>200 \mathrm{mg} / \mathrm{dl}$ (42.1\% males and 57.9 females, and 218 of patients $(63.4 \%)$ had LDL of $\geq 115 \mathrm{mg} / \mathrm{dl}(43.1 \%$ males and $56.9 \%$ females, and 198 of patients $(57.6 \%)$ had HDL of $<40 \mathrm{mg} / \mathrm{dl}$ ( $57.1 \%$ males and $42.9 \%$ females), and only 158 of patients (45.9\%) had serum triglycerides of $<150 \mathrm{mg} / \mathrm{dl}$ ( $38 \%$ males and $62 \%$ females. There was statistically significant increment of HDL and triglycerides in females as shown in table (1).

Table(1) Frequency of dyslipidemia according to gender distribution in Hypertension patients.

\begin{tabular}{|c|c|c|c|c|c|c|c|c|}
\hline \multirow{2}{*}{ Variables } & \multirow{2}{*}{ Subvaraibles } & \multicolumn{2}{|c|}{ Male } & \multicolumn{2}{|c|}{ Female } & \multicolumn{2}{|c|}{ Total } & \multirow{2}{*}{ P-value } \\
\hline & & No. & $\%$ & No. & $\%$ & No. & $\%$ & \\
\hline \multirow{2}{*}{$\begin{array}{l}\text { Total } \\
\text { Cholesterol }\end{array}$} & $>200 \mathrm{mg} / \mathrm{dl}$ & 72 & 42.1 & 99 & 57.9 & 171 & 49.7 & \multirow{2}{*}{0.230} \\
\hline & $\leq 200 \mathrm{mg} / \mathrm{dl}$ & 84 & 48.6 & 89 & 51.4 & 173 & 50.3 & \\
\hline \multirow{4}{*}{ LDL } & $\geq 115 \mathrm{mg} / \mathrm{dl}$ & 94 & 43.1 & 124 & 56.9 & 218 & 63.4 & \multirow{4}{*}{$* 0.621$} \\
\hline & $<115-100 \mathrm{mg} / \mathrm{dl}$ & 32 & 51,6 & 30 & 48.4 & 62 & 18.0 & \\
\hline & $<100-70 \mathrm{mg} / \mathrm{dl}$ & 25 & 45.5 & 30 & 54.5 & 55 & 16.0 & \\
\hline & $<70 \mathrm{mg} / \mathrm{dl}$ & 5 & 55.6 & 4 & 44.4 & 9 & 2.6 & \\
\hline
\end{tabular}


Cont... Table(1) Frequency of dyslipidemia according to gender distribution in Hypertension patients.

\begin{tabular}{|c|c|c|c|c|c|c|c|c|}
\hline \multirow{2}{*}{ HDL } & $\geq 40 \mathrm{mg} / \mathrm{dl}$ & 43 & 29.5 & 103 & 70.5 & 146 & 42.4 & \multirow{2}{*}{$<0.0001$} \\
\hline & $<40 \mathrm{mg} / \mathrm{dl}$ & 113 & 57.1 & 85 & 42.9 & 198 & 57.6 & \\
\hline \multirow[t]{3}{*}{ Triglycerides } & $<150 \mathrm{mg} / \mathrm{dl}$ & 60 & 38.0 & 98 & 62.0 & 158 & 45.9 & \multirow[t]{3}{*}{0.039} \\
\hline & $150-199 \mathrm{mg} / \mathrm{dl}$ & 48 & 52.7 & 43 & 47.3 & 91 & 26.5 & \\
\hline & $\geq 200 \mathrm{mg} / \mathrm{dl}$ & 48 & 50.5 & 47 & 49.5 & 95 & 27.6 & \\
\hline
\end{tabular}

By Fisher Exact test.*

Patients with BMI of $\geq 30 \mathrm{Kg} / \mathrm{m} 2$ had higher total cholesterol $(212.38 \pm 54.84) \mathrm{mg} / \mathrm{dl}$ and HDL level (38.25 \pm 11.86$)$ $\mathrm{mg} / \mathrm{dl}$, while patients with BMI of $25-29.9 \mathrm{Kg} / \mathrm{m} 2$ had higher level of triglycerides $(190.44 \pm 128.34) \mathrm{mg} / \mathrm{dl}$ and patients with BMI of 18.5-24.9 Kg/m2 had higher level of LDL (144.71 \pm 44.84$) \mathrm{mg} / \mathrm{dl}$ as shown in table(2). The differences were statistically not significant.

Table(2) Lipid profiles (mean \pm SD) among hypertension patients according to BMI.

\begin{tabular}{|l|l|l|l|l|}
\hline Variables & $\mathbf{1 8 . 5 - 2 4 . 9 ~ K g / m 2}$ & $\mathbf{2 5 - 2 9 . 9 ~ K g / m 2}$ & $\mathbf{3 0 \leq}$ & Kg/m2 \\
\hline Total cholesterol (mg/dl) & $210 \pm 46.21$ & $200.37 \pm 41.57$ & $212.38 \pm 54.84$ & 0.132 \\
\hline HDL (mg/dl) & $36.86 \pm 7.65$ & $37.63 \pm 8.08$ & $38.25 \pm 11.86$ & 0.174 \\
\hline LDL (mg/dl) & $144.71 \pm 44.84$ & $127.46 \pm 33.03$ & $134.06 \pm 41.22$ & 0.815 \\
\hline Triglycerides (mg/dl) & $123.71 \pm 32.34$ & $190.44 \pm 128.34$ & $179.88 \pm 114.87$ & 0.133 \\
\hline
\end{tabular}

Smoker patients in this study had highest ASCVD risk score (12.65 $\pm 6.63 \%)$ followed by former smokers $(7.36 \pm 3.56 \%)$ and non-smokers $(6.02 \pm 4.16 \%)$ respectively as shown in table (3). The difference was statistically significant.

Table(3) ASCVD-score (Mean \pm SD) among hypertension patients according to smoking status.

\begin{tabular}{|l|l|l|l|l|}
\hline Variable & Smokers & Former & Non-smoker & P-value \\
\hline ASCVD score (\%) & $12.65 \pm 6.63$ & $7.36 \pm 3.56$ & $6.02 \pm 4.16$ & $<0.0001$ \\
\hline
\end{tabular}

In the present study there were 107 (31.1\%) patients with hypertension had very high risk for developing ASCVD, most of them were males (65\%), while 128 (37.2\%) patients had moderate risk for developing ASCVD, most of them were females $(71.9 \%)$ as shown in table (4). The difference was statistically significant.

Table (4) ASCVD risk according to 2016 ESC/EAS guidelines and gender distribution in hypertension patients.

\begin{tabular}{|l|l|l|l|l|l|l|}
\hline \multirow{2}{*}{ Variables } & \multicolumn{2}{l}{ Male } & \multicolumn{2}{l|}{ Female } & \multicolumn{2}{l|}{ Total } \\
\cline { 2 - 7 } & No. & $\%$ & No. & $\%$ & No. & $\%$ \\
\hline Low risk & 7 & 63.6 & 4 & 36.4 & 11 & 3.2 \\
\hline Moderate risk & 36 & 28.1 & 92 & 71.9 & 128 & 37.2 \\
\hline High risk & 48 & 49.0 & 50 & 51.0 & 98 & 28.5 \\
\hline Very high risk & 65 & 60.7 & 42 & 39.3 & 107 & 31.1 \\
\hline
\end{tabular}


Only 76 (22.1\%) of hypertension patients were on statin therapy for hyperlipidemia and only $18(23.7 \%)$ of them reaching target LDL level according to $2016 \mathrm{ESC} /$ EAS guidelines. While $268(77.9 \%)$ of hypertension patients had no statin therapy and only $65(24.3 \%)$ of them had LDL level within target as shown in figure (1). The difference between treated and non- treated patients in reaching targeted LDL level was statistically not signicant.

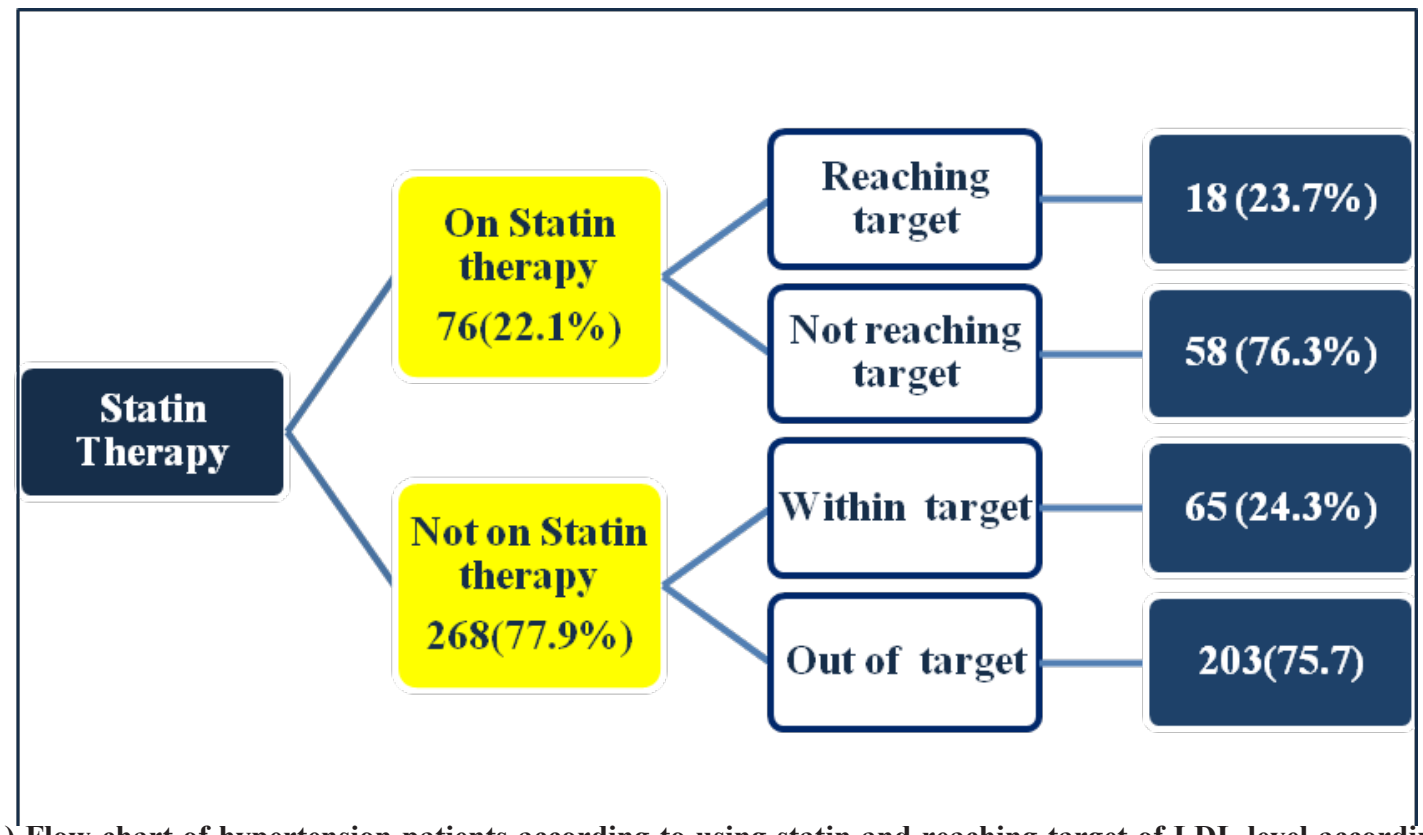

Figure (1) Flow-chart of hypertension patients according to using statin and reaching target of LDL level according to 2016 ESC/EAS guidelines.

\section{Discussion}

In the present study, females had levels of HDL and triglycerides significantly higher than that in males , while there was no significant difference in regard to levels of total cholesterol and LDL. Previous study ${ }^{[16,17]}$ reported that sex -related differences in triglycerides, total cholesterol, HDL and LDL levels, other study ${ }^{[18]}$ found no sex -related differences in TC and LDLC in subjects aged 50 years and more but females had lower level of triglycerides and HDL than males. In another study ${ }^{[19]}$ females aged 18 years and more had lower levels of triglycerides and LDL and higher level of HDL than males.

In the present study there was no significant differences in levels of total cholesterol, triglycerides, LDL and HDL among different BMI groups. Associations of adiposity at baseline and dyslipidemia have been shown in large prospective studies ${ }^{[20-24]}$, however there is inverse relationship between smoking and body weight ${ }^{[25]}$, and smoking associated with low HDL [26], for this reason and perhaps using of statin therapy by some patients in this study may lead to these results.

The present study revealed the effect of smoking on raising ASCVD risk and this is in agreement with other studies ${ }^{[27-30]}$. Also this study revealed that most of very high risk group for developing cardiovascular disease were men and this is in agreement of other studies ${ }^{[20-24]}$.

The present study revealed that only $22.1 \%$ of Iraqi hypertension patients in Tikrit City on statin therapy and only $23.7 \%$ of them reaching target of LDL level , while $77.9 \%$ of them are not on any treatment for hyperlipidemia, although $75.7 \%$ of them are out of target of LDL level according to 2016 ESC/EAS guidelines. This is comparable to a study done in Russia ${ }^{[31]}$.

\section{Conclusion}

Hyperlipidemia is very prevalent in hypertension patients in Tikrit City, despite that only one of five receiving treatment and only one of four from those who received treatment reaching the target of LDL level according to $2016 \mathrm{ESC} / \mathrm{EAS}$ guidelines, and three of four of those who are on no treatment are out of the target. This is a major health problem need attention. 
* Conflict of Interest - (nil - There are "NO CONFLICT OF INTEREST").

* Source of Funding - By all researchers (self).

* Ethical Clearance: Committee members are approved to perform a study about

"Study of dyslipidemia in Iraqi Hypertension patients in Tikrit city"

\section{References}

1- Williams B, Mancia G, Spiering W. 2018 ESC/ ESH Guidelines for the management of arterial hypertension, European Heart Journal ,2018;39: 3021-3104.

2- Singh S, Shankar R, Singh GP, Prevalence and Associated Risk Factors of Hypertension:A CrossSectional Study in Urban Varanasi, International Journal of Hypertension, 2017; Article ID 5491838,10 pages.

3- Chobanian AV, Bakris GL, Black HR, et al. Seventh report of the Joint National Committee on prevention, de-tection, evaluation, and treatment of high blood pressure. Hypertension. 2003;42(6):1206-1252.

4- Erem C, Hacihasanoglu A, Kocak M, Deger O,Topbas M,"Prevalence of prehypertension and hypertension and associated risk factors among Turkish adults: trabzon hypertension study,"Journal of Public Health,2009;31(1):47-58.

5- Abebe SM, Berhane Y, Worku A, Getachew A,"Prevalence and associated factors of hypertension: acrossectional communitybased study inNorthwest Ethiopia,"PLoSONE,2015;10(4): Article ID e0125210.

6- Mishra CP, Kumar S, "Risk factors of hypertension in a rural area of Varanasi,"Indian Journal of Preventive and SocialMedicine, 2011;42(1):101111.

7- Ahmed A, Rahman M, Hasanetal R, "Hypertension and associated risk factors in some selected rural areas ofBangladesh,"International Journal of Research in Medical Sciences, 2014;2(3): 925.

8- MozaffarianD, Benjamin EJ, Go AS, et al. Heart disease and stroke statistics-2016 update: A report from the American Heart Association. Circulation, 2016 Jan 26;133(4):e38-360.
9- WHO STEPS noncommunicable disease risk factor surveillance. www.who.int/chp/steps: 6-3A-1 fact sheet.

10- Musunuru K. Atherogenic dyslipidemia: cardiovascular risk and dietary intervention. Lipids. 2010;45:907-914.

11- Haffner SM. Diabetes, hyperlipidemia, and coronary artery disease. Am J Cardiol. 1999;83(9B):17F$21 \mathrm{~F}$.

12- Libby P. Inflammation in atherosclerosis. Nature. 2002;420:868-874.

13- Reina SA, Llabre MM, Allison MA, Wilkins JT, Mendez AJ, Arnan MK, et al. HDL cholesterol and stroke risk: the Multi-Ethnic Study of Atherosclerosis. Atherosclerosis. 2015;243:314319.

14- Ademolu A, Correlation between Hyperlipidemia and Hypertension, Mean Arterial Pressure, Pulse Pressure among Africans. Endocrinol Metab Int J ,2017;5(6): 00140. DOI: 10.15406/ emij.2017.05.00140.

15- Catapano AL, Graham I, Backer GD, Wiklund O, Chapman MJ, Arno HD. 2016 E SC/EAS guidelines for management ofdyslipedemias, European Heart Journal,2016; 37:2999-3058.

16- Szymańska JO, Woźniak EH, Piątkowska I, Malara M. Effects of age, gender and physicalactivity on plasma lipid profile. Biomedical Human Kinetics.2011;3:1-5.

17- Ardern CI, Katzmarzyk PT, Janssen I, Leon AS, Wilmore JH,Skinner JS, Rao DC, Despres JP , Rankinen T, Bouchard C. Race and sex similarities in exercise-induced changes in blood lipids and fatness. Med.Sci.Sports Exerc. 2004;36: 16101615 .

18- Habib SS, Aslam M, Hameed W. Gender differences in lipids and lipoprotein(a)profiles in healthy individuals and patients with type 2 diabetes mellitus. Pak.J.Physiol.2005;15:1-19.

19- Garelnabi M, VeleJdar E, Abramson J, WhiteWelkley J, Santanam N, Weintraub W, Parthasarathy S. Physical inactivity and cardiovascular risk: baseline observations from men and premenopausal women. J.Clin.Lab.Anal.2010; 24:100-105.

20- Higgins M, Kannel W, Garrison R, Pinsky J, Stokes J Hazards of obesity: the Framingham experience. Acta Med Scand Suppl. $1988 ; 723$ :23-6. 
21- Willett WC, Manson JE, Stampfer MJ, et al. Weight change, and coronary heart disease in women: risk within the "normal" weight range. JAMA.1995;273:461-5.

22- Gillum RF, Taylor HL, Brozek J, Polansky P, Blackburn H.Indices of obesity and blood pressure in young men followed 32 years. J Chronic Dis. 1982;35:211-9.

23- Witteman JC, Willett WC, Stampfer MJ, et al. A prospective study of nutritional factors and hypertension among US women. Circulation. 1989;80:1320 -7.

24- Manson JE, Colditz GA, Stampfer MJ, et al. A prospective study of obesity and risk of coronary heart disease in women. N Engl J Med. 1990 ;322:882-9.

25- Albanes D, Jones Y, Micozzi MS, Mattson ME. Associations between smoking and body weight in the US population: analysis of NHANES II. Am J Public Health.1987;77:439-44.

26- Garrison RJ, Kannel WB, Feinleib M, Castelli WP, McNamara PM, Padgett SJ.Cigarette smoking and HDL cholesterol: the Framingham offspring study. Atherosclerosis. 1978;17:25-30.

27- Honjo K, Iso H, Tsugane S, Tamakoshi A, Satoh H, Tajima K, Suzuki T, Sobue T. The effects of smoking and smoking cessation on mortality from cardiovascular disease among Japanese: Pooled analysis of three large-scale cohort studies in Japan. Tob Control 2010; 19: 50-57.

28- Lawlor DA, Song YM, Sung J, Ebrahim S, Smith GD. The association of smoking and cardiovascular disease in a population with low cholesterol levels: A study of 648,346 men from the Korean national health system prospective cohort study. Stroke J. Cereb. Circ. 2008;39: 760-767.

29- Tan J, Zhang X, Wang W, Yin P, Guo X, Zhou M. Smoking, Blood Pressure, and Cardiovascular Disease Mortality in a Large Cohort of Chinese Men with 15 years Follow-up. Int. J. Environ. Res. Public Health. 2018;15: 1026.

30- Mallaina P, Lionis P, Rol H, Imperiali R, Burgess A, Nixon M, Malvestiti FM. Smoking cessation and the risk of cardiovascular disease outcomes predicted from established risk scores: Results of the Cardiovascular Risk Assessment among Smokers in Primary Care in Europe (CV-ASPIRE) Study. Public Health.2013;13:362.

31- Cybulsky M, Cook S, Kontsevaya AV, Vasiljev M, Leon DA. Pharmacological treatment of hypertension and hyperlipidemia in Izhevsk, Russia. Cardiovascular Disorders. 2016; 16:122. 